\title{
Continuous Wave Diode Laser Surface Texturing of Austenitic and Pearlitic Steels
}

\author{
Sulthan Mohiddin Shariff ${ }^{*}$, Suresh Koppoju', Tapan Kumar Pal'2, Padmanabham Gadhe1, \\ Shrikant Viswanath Joshi1 \\ ${ }^{1}$ International Advanced Research Centre for Powder Metallurgy and New Materials (ARCI), Hyderabad, India \\ ${ }^{2}$ Department of Metallurgical and Materials Engineering, Jadavpur University, Kolkata, India \\ Email: ${ }^{*}$ knl.sms@gmail.com
}

Received 22 May 2015; accepted 24 October 2015; published 27 October 2015

Copyright (C) 2015 by authors and Scientific Research Publishing Inc.

This work is licensed under the Creative Commons Attribution International License (CC BY).

http://creativecommons.org/licenses/by/4.0/

(c) (i) Open Access

\begin{abstract}
Microstructuring of steel resulting in directional solidification and texturing, previously observed in various metallic materials during pulsed laser processing, melt-spinning, high-gradient liquid metal melting, zone melting etc., is reported for the first time in continuous wave diode laser processing of steels. Influence of laser interaction time on surface morphology/topology of austenitic manganese and pearlitic steels is investigated utilizing a wide rectangular multi-mode diode laser beam. X-ray diffraction analysis of the laser treated austenitic steel surface showed strong texturing influence, with preferred crystallographic orientation of $\gamma$-Fe crystals in the (200) plane, which increased with interaction time. In case of pearlitic steel, no such texturing influence could be observed. The free surface topologies were also observed to be different in each case, with wellaligned domes of $\gamma$-Fe observed in laser treated austenitic steel as compared to randomly oriented fine domes of metal oxides in pearlitic one. In situ surface temperature measurement during laser irradiation indicated higher temperature on pearlitic steel than in austenitic manganese steel owing to its lower effective thermal conductivity associated with higher oxide film formation.
\end{abstract}

\section{Keywords}

Diode Laser, Texturing; Pearlitic Steel, Austenitic Manganese Steel, Directional Solidification, Oxidation, Surface Morphology, Surface Topology

\section{Introduction}

Surface morphology/topology is a significant factor influencing the optical, tribological, mechanical and many

"Corresponding author. 
other functional properties of a material. In recent times, the ability to modify the above has been exploited to provide technological advances in various fields like electronics, energy, tribology, biology, information technology etc. Due to the precise control of spatial and temporal parameters afforded by a laser, well-defined textured surfaces can be potentially realized depending on the material and the processing conditions involved [1][8]. Additionally, the extremely high cooling rates possible with laser processing induce some unusual exotic and non-equilibrium microstructures and surface textures [9] that stimulate great research interest because of the potential to realize novel properties and functions.

The techniques tried for texturing and producing directionally solidified microstructures have included laser-based methods like micro-fabrication, melting, ablation etc. [10]-[12]. The influence of the laser and the thermophysical properties of the substrate material have been found to be key determinants. In materials such as Ni-base super alloys and alumina-zirconia, directionally solidified single crystals or eutectics are produced by laser surface irradiation with strong texturing influence on account of the induced high thermal gradients [13][16]. The high temperature gradients possible in rapid laser melting, with a wide range of G (temperature gradient)/ $\mathrm{R}$ (solidification rate) ratios at the solid-liquid interface, facilitate production of refined solidification structures with well-defined orientation relationships among the constituent phases [17]-[19]. Bruzzone and coworkers reported various techniques, including laser surface modification, for producing such engineered surfaces on diverse materials that could be gainfully utilized for exploiting various functional properties [20]. Various phenomena, like thermocapillary stress generation, ablation, surface tension, Marangoni effects in liquid flow, vapor condensation etc., were observed to play a predominant role in governing the properties of such engineered textured surfaces.

Liu and co-workers reported directional growth of the metastable $\gamma$ phase in $\mathrm{CO}_{2}$-laser remelted Ti-Al [19]. Hua and co-workers produced textured flower-like surface morphologies by irradiating a pulsed YAG laser on DF-2 cold worked steel [2]. Vilar and co-workers observed strong textured crystallographic orientation in $\mathrm{Al}_{3} \mathrm{Nb}$ in Al-Nb coatings produced by laser-alloying under critical conditions [17]. Boettinger critically explained the solidification science associated with the formation of directionally solidified structures and crystal anisotropy effects in melt microstructures [13]. Lu and co-workers produced epitaxial layers in the direction of laser movement in $\mathrm{CO}_{2}$ laser glazed layers of Ni-based super alloy and attributed to the preferential growth associated with the solidification mechanism under high cooling rates [21]. Semak and co-workers illustrated the influence of temporal conditions of laser on the resulting temperature field in the beam interaction zone to induce surface morphological effects [7]. Lickschat and co-workers studied the effect of pico and femtosecond laser pulse irradiation on texturing of steel [4]. The above study also demonstrated the influence of thermal diffusion controlled by pulse duration on resulting cavities on the ablated surfaces. Similarly, Brown and co-workers reported the influence of pulse duration on the resulting nanometer-scale features noted on the textured surface of platinum [3].

Austenitic manganese steel (commonly known as Hadfield steel) is one such interesting alloy used in various sectors like earthmoving, railroading, mineral processing etc. due to its outstanding properties like high toughness, excellent work hardenability and wear resistance. Various techniques like laser cladding, melt-spinning, hardening etc. have been attempted to exploit its unique structural properties. Tjong and Tsang reported formation of columnar and equiaxed dendrites of austenite in laser melted layer with precipitation of $\beta$-Mn and K-phase, after ageing, depending on the conditions employed [22]. Chen and co-workers successfully produced rapidly solidified $\mathrm{Fe}-\mathrm{Cr}-\mathrm{Mn}-\mathrm{C}$ based alloy ribbons by adopting a high-speed melt-spinning technique [23]. However, no surface texturing studies involving laser-based rapid solidification processing of the austenitic or pearlitic steel are available in literature.

In view of the increasing relevance of understanding the texturing effects during laser treatment of steels and to exploit the favorable properties that they can yield, the present study aims to assess the influence of diode laser processing on texturing of austenitic manganese and pearlitic steels. Such a texturing study involving two different steels having contrasting thermophysical properties is expected to facilitate an improved understanding. The effect of interaction time on the evolving surface topology/texture and microstructure utilizing a wide area multimode diode laser beam is specifically investigated.

\section{Experimental Procedures}

The steel specimens used for experimentation were fabricated from actual rail sections employing EDM wirecutting. Flat coupons of size $100 \mathrm{~mm} \times 100 \mathrm{~mm}$ were first sectioned in such a way that no adverse effects due to 
decarburization, oxidation etc was present and then subjected to surface grinding to $1.2 \mu \mathrm{m}$ Ra finish. The chemical composition of pearlitic rail steel (PRS) and austenitic manganese rail steel (AMRS) used are depicted in Table 1. A fully austenitic microstructure with completely dissolved $\mathrm{Mn}$ and $\mathrm{C}$ is characteristic of AMRS on account of its solution treated condition.

The flat steel coupons were subjected to laser surface treatment (irradiation) under an argon shroud by employing a continuous wave (CW) high power diode laser (Laserline $\mathrm{GmbH}$, Germany) integrated to a 6-axis robotic work station (Reis Robotics GmbH, Germany). The multi-mode 915 - $980 \mathrm{~nm}$ diode laser beam (Gaussian mode in fast axis and top-hat mode in slow axis) transferred through a $1500-\mu \mathrm{m}$ fiber optic cable (HighYag $\mathrm{GmbH}$, Germany) was tailored into a rectangular spot of $17 \mathrm{~mm} \times 2 \mathrm{~mm}$ (Full Width Half Maximum) by employing special setup comprising collimating, homogenizing and focusing optics. Prior to laser irradiation with varying interaction times, laser-power-ramping experiments at a fixed scanning speed of $6 \mathrm{~mm} / \mathrm{s}$ in continuous mode were carried out with in situ surface temperature measurement utilizing an E-Maqs camera based Lasertronic-Lampocpro system (Fraunhofer IWS, Germany). Table 2 shows the processing conditions adopted. All experiments were carried out under a laminar flow of argon shroud using a special nozzle setup designed with $20 \mathrm{~mm} \times 3 \mathrm{~mm}$ orifice under a pressure of 3-bar to provide adequate protection from atmospheric contamination. After assessing the influence of laser power on melting and surface temperature effects during in situ power ramping experiments, fresh experiments were conducted at a fixed laser power of $6000 \mathrm{~W}$ and varying interaction times ranging from $3.3 \mathrm{~ms}-100 \mathrm{~ms}$ on both PRS and AMRS substrates. The range of interaction time was chosen such that surface texture effects produced under conditions ranging from no-melting zone to substantial melting could be assessed. Table 3 depicts various thermophysical and mechanical properties (compiled from various literature reports) of the steels used for the study [24]-[33].

Table 1. Chemical composition of pearlitic (PRS) and austenitic (AMRS) steels used in the study.

\begin{tabular}{ccccccccccccc}
\hline Designation & C & Mn & Si & Al & S & Fe & $<0.02$ & $<02$ & Bal. \\
PRS & 0.67 & 1.13 & 0.27 & $<0.01$ & $<0.01$ & $<0.02$ & $<0.02$ & Bal. \\
AMRS & 1.34 & 13.6 & 0.45 & $<$
\end{tabular}

Table 2. Processing conditions employed for both power-ramping and texturing experiments.

\begin{tabular}{|c|c|c|}
\hline Diode laser beam spot (FWHM) & \multicolumn{2}{|c|}{$17 \mathrm{~mm} \times 2 \mathrm{~mm}$} \\
\hline Shroud gas & \multicolumn{2}{|c|}{ Argon at 3 bar } \\
\hline Scanning speed (for power ramping experiments) & \multicolumn{2}{|c|}{$6 \mathrm{~mm} / \mathrm{s}$} \\
\hline Laser power (for power ramping experiments) & \multicolumn{2}{|c|}{$500-1700 \mathrm{~W}$} \\
\hline Temperature range (for power ramping experiments) & \multicolumn{2}{|c|}{$800^{\circ} \mathrm{C}-1320^{\circ} \mathrm{C}$} \\
\hline Laser power (for texturing experiments) & \multicolumn{2}{|c|}{$6000 \mathrm{~W}$} \\
\hline Interaction time (for texturing experiments) & \multicolumn{2}{|c|}{$3.3-100 \mathrm{~ms}$} \\
\hline Sample condition & \multicolumn{2}{|c|}{ Surface ground to $1.2 \mu \mathrm{m} \mathrm{R}_{\mathrm{a}}$ finish } \\
\hline Property & PRS & AMRS \\
\hline Density, $\mathbf{g} / \mathrm{cm}^{3}$ & 7.84 & 7.88 \\
\hline Specific heat, $\mathbf{J} /\left(\mathrm{Kg}^{\circ}{ }^{\circ} \mathrm{C}\right)$ & 674 & 502 \\
\hline Thermal conductivity, $\mathrm{W} /\left(\mathrm{m}-{ }^{\circ} \mathrm{C}\right)$ & 50.5 & 13 \\
\hline Thermal expansion co-efficient $\left(0^{\circ} \mathrm{C}-600^{\circ} \mathrm{C}\right), \times 10^{-6}{ }^{\circ} \mathrm{C}^{-1}$ & 10.8 & 21.5 \\
\hline Hardness, $\mathrm{HV}_{0.5}$ & $310-360$ & $315-395$ \\
\hline Elastic modulus, GPa & 210 & 186 \\
\hline Solidus temperature, ${ }^{\circ} \mathrm{C}$ & 1287 & 1135 \\
\hline Martensite start temperature $\mathbf{M}_{\mathrm{s}},{ }^{\circ} \mathrm{C}$ & 263 & -193 \\
\hline Critical austenetization temperature $\mathbf{A}_{\mathrm{C} 3},{ }^{\circ} \mathrm{C}$ & 765 & 983 \\
\hline Thermal diffusivity, $10^{-6} \times \mathrm{m}^{2} / \mathrm{s}$ & 5.1 & 3.8 \\
\hline
\end{tabular}


After laser irradiation, as-treated surfaces were subjected to surface topology/morphology evaluation utilizing a 3D non-contact optical profilometer (Zygo Corporation, USA), an Optical Microscope (OM) and a Scanning Electron Microscope (SEM) (Hitachi Corporation, Japan). Relevant textured surface features like average surface roughness $\left(\mathrm{R}_{\mathrm{a}}\right)$, average peak-to-valley height $(\mathrm{PV})$, average surface waviness $\left(\mathrm{W}_{\mathrm{a}}\right)$ etc., were also measured. In order to analyze the melt depth/hardened layer depth and sub-surface microstructure of the treated surfaces, metallographic samples were sectioned from the cross-section of the treated tracks using a slow-speed Isomet cutting machine and the samples mounted and ground as per standard metallographic sample preparation methods. Few samples were also analyzed for elemental distribution in dendritic and inter-dendritic regions of the microstructure using Energy Dispersive Spectrometer (EDS) attached to the SEM. Phase and surface texture analysis of treated surfaces (both in polished and unpolished conditions) was carried out utilizing X-ray Diffractometer (XRD) system (Bruker AXS, Germany) to understand phase changes as well as texturing effects due to laser treatment at different interaction times.

\section{Results and Discussions}

\subsection{Analysis of Substrate Steels}

Figure 1 illustrates microstructure, surface morphology and surface topology of untreated PRS and AMRS steel surfaces prior to laser processing. As the surface preparation prior to laser irradiation is same in case of both the
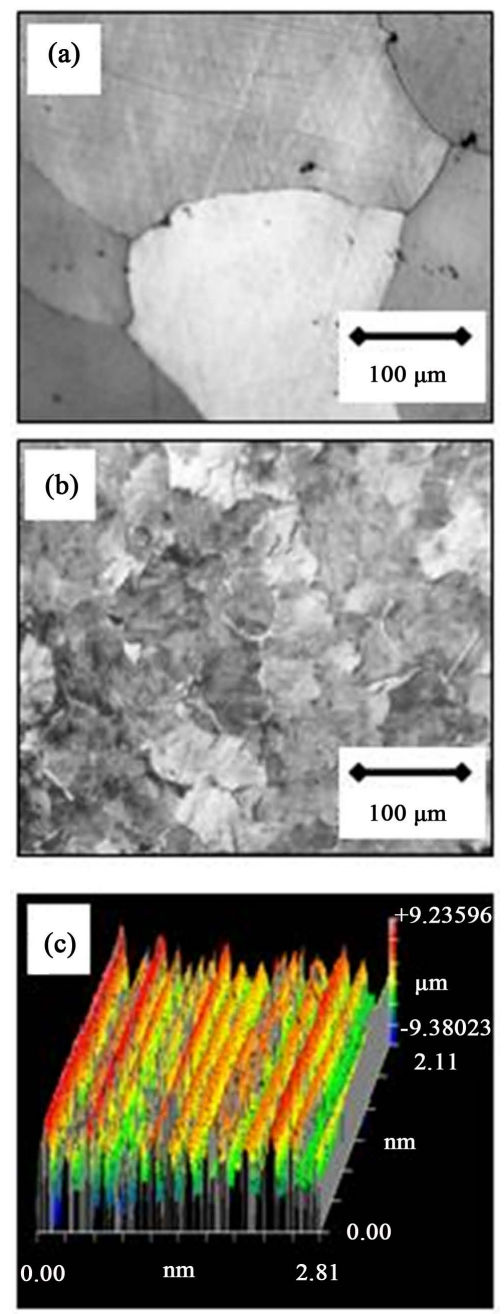

Figure 1. Microstructure and surface topologies of untreated steels: (a) AMRS microstructure; (b) PRS microstructure; (c) PRS/AMRS 3D surface topology profile. 
steels, 3D surface profile presented in Figure 1(c) remains same. The microstructure of AMRS depicted in Figure 1(a), delineated due to chemical etching indicate, possibly large grains of austenite with grain boundary network of carbides of Fe and Mn. The microstructure obtained was similar to that observed in normal Hadfield steels obtained due to solution treatment as reported in various studies [34]-[37]. The presence of high amounts of carbon and manganese in AMRS are principally responsible for stabilization of austenite at room temperature [38] [39]. Grain size measurement in microstructure of the AMRS steel indicated presence of coarse austenitic grains in the range of $160-400 \mu \mathrm{m}$. Phase analysis of the AMRS reported by same authors in an earlier study also indicated presence of large grains of austenite with thin grain boundary of carbide network [28]. Figure 1(b) depicting microstructure of PRS indicates fully pearlitic lamellae with few ferritic islands. Phase analysis of the PRS reported previously by the same authors indicated almost 97\% pearlite [40] [41]. The dark etched regions in between pearlitic lamellae comprise of ferrite and observed to be $2 \%-3 \%$. The interlamellar spacing in pearlite of PRS evaluated by adopting standard metallographic methods, described elsewhere by Clayton [42], was found to be $260 \pm 40 \mathrm{~nm}$. The surface topographic profile of PRS/AMRS depicted in Figure 1(c) shows grinding furrows/striations. The average surface roughness $\left(R_{a}\right)$ and average peak-to-valley height $(P V)$ values of the untreated substrate steel surface were found to be about $1.1 \mu \mathrm{m}$ and $5 \mu \mathrm{m}$ respectively.

\subsection{In Situ Surface Temperature Analysis during Power-Ramping Experimentation}

Figure 2 shows the in situ surface temperature measurement graphs obtained during power-ramping experimentation on both PRS and AMRS along with treated surface images. After conducting the power-ramping experimentation, few micro-hardness measurements were also carried out on treated surfaces to assess any hardening effects. It is clear that the measured surface temperature (from E-Maqs camera) was always found lower

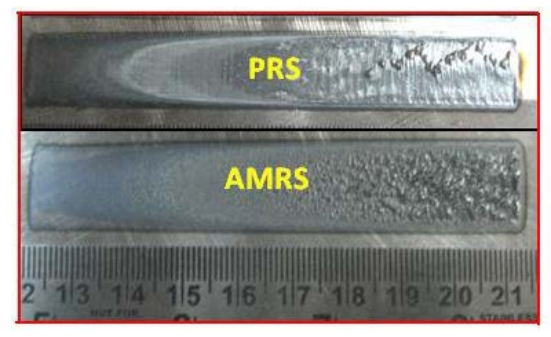

(a)

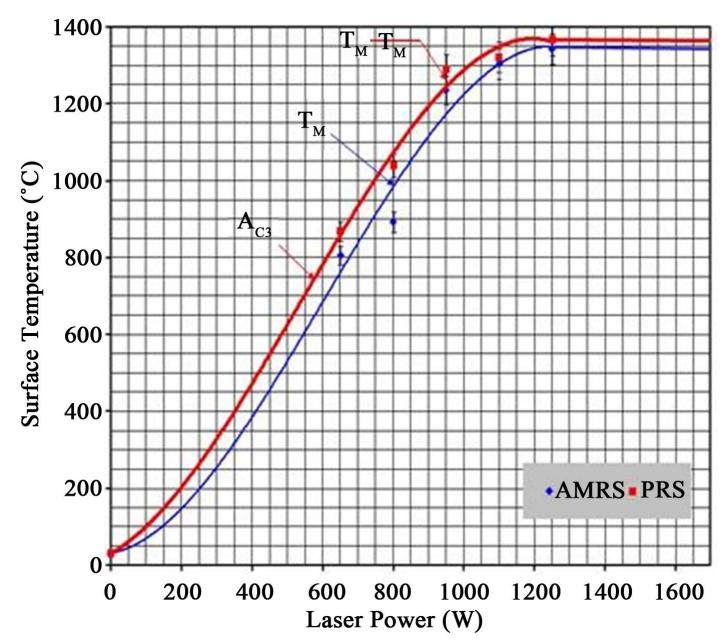

(b)

Figures 2. (a) Surface morphologies of laser-treated tracks obtained with power-ramping experimentation; (b) variation in surface temperature with laser power measured during power-ramping experiments utilizing E-Maqs Lampocpro system $\left(\mathrm{T}_{\mathrm{M}}\right.$ indicates melting point and $\mathrm{A}_{\mathrm{C} 3}$ indicates hardening temperature). 
in AMRS as compared to PRS. Although room-temperature thermal conductivity of AMRS is nearly one-third of PRS (refer to Table 3), its effective thermal conductivity enhances on account of its low oxidation affinity associated with higher carbon and manganese contents. PRS is more prone to formation of a surface oxide scale (with higher amount of iron oxides) than AMRS and thereby leading to lower effective thermal conductivity and higher laser absorptivity at the surface and correspondingly rise in surface temperature. Indeed, surface morphology (depicted in Figure 2(a)) exhibiting darker discoloration in PRS than in AMRS corroborates the above effect. Studies involving laser irradiation of steels with different surface treatment conditions also reported similar effects of increase in surface temperature associated with enhanced surface absorptivity and reduced effective thermal conductivity governed by the type and amount of oxide film formed on the surface [43] [44]. The $\mathrm{A}_{\mathrm{C} 3}$ temperature in case of PRS and $\mathrm{T}_{\mathrm{M}}$ temperatures in PRS/AMRS were identified based on observation of increase in surface hardness and commencement of surface undulations on laser treated tracks. The evaluated critical austenetization $\left(\mathrm{A}_{\mathrm{C} 3}\right)$ and solidus $\left(\mathrm{T}_{\mathrm{M}}\right)$ temperatures from the curve fitting for PRS showed values of about $743^{\circ} \mathrm{C}$ and $1245^{\circ} \mathrm{C}$ respectively. The points presented in the graphs with error bars are the actual values measured and averaged from three trials. In case of AMRS, the solidus temperature $\left(\mathrm{T}_{\mathrm{M}}\right)$ evaluated was found to be about $990^{\circ} \mathrm{C}$.

The optical images of treated surfaces presented in Figure 2 evidently show distinguishably different morphologies produced on account of variation in chemistry of steels. It is clear that melting commenced at an early stage in case of AMRS (at about $990^{\circ} \mathrm{C}$ ) as compared to PRS (at about $1245^{\circ} \mathrm{C}$ ) owing to low solidus temperature of AMRS associated with presence of high $\mathrm{Mn}$ and $\mathrm{C}$ contents in steel. Indeed, the measured solidus temperatures $\left(\mathrm{T}_{\mathrm{M}}\right)$ from E-Maqs system in both the steels are also close in agreement with the values reported in literature [26] [30]. The corresponding laser power required for commencement of melting in PRS and AMRS were observed to be $795 \mathrm{~W}$ and $950 \mathrm{~W}$ respectively. Indeed, presence of higher amounts of $\mathrm{Mn}$ and $\mathrm{C}$ contents in AMRS enhances the temperature gradient in the liquid and thereby render constitutional super cooling of melt with ease. Thus many protrusions on the melted regions are quite discernible in case of laser treated AMRS surface with their quick commencement (at low surface temperatures) as compared to that of PRS. No improvement in hardness could be observed on the surface of AMRS on account of no martensitic transformation as against high surface hardness of 800 - $870 \mathrm{HV}$ observed in PRS. This is convergent with ease of austenite stabilization at room temperature in AMRS, associated with $-193^{\circ} \mathrm{C} \mathrm{M}_{\mathrm{s}}$, as against martensitic transformation in PRS, whose $\mathrm{M}_{\mathrm{s}}$ Temperature is $263^{\circ} \mathrm{C}$ (depicted in Table 3).

Another important feature discernible is variation of surface morphology with surface temperature evident from the relatively darker discoloration in hardened region of PRS surface compared to that of AMRS. This could be presumably due to variation in material absorptivity and oxide scale formation effect (reported later in XRD analyses of as-treated surfaces). Although laser treatment has been carried out under inert gas shielding, the propensity for oxidation increases with temperature and the formation of oxide layer and its growth rate is found to be dependent on alloying elements of steel. Various reported studies on laser surface hardening/melting also reported similar formation of oxide layers despite processing under inert atmospheres [40] [44] [45]. The presence of low Mn and C constituents in PRS could plausibly oxidize the surface easily accompanied with oxide film growth and thereby enhance abosptivity. Indeed, in a similar study involving laser melting of stainless steels, the ease of formation of manganese oxides was found favorable at low temperatures as compared to iron oxides at higher temperature owing to their low Gibbs free energies of formation [1]. Thus PRS favored formation of higher amounts of iron oxides than AMRS as evident from darker discoloration in the hardened surfaces processed at low surface temperatures. With further increase in surface temperature, in melting regime, mixing of oxide products with melt and evaporation effects will come into vogue that manifest in surface undulations. In similar reported studies involving YAG laser processing of steels, similar morphological features of protrusions and crests were observed on melted surface and attributed to scattered localized melting, evaporation and some turbulent convective heat transfer effects [2] [46].

\subsection{Surface Texture Analysis}

Further to the analysis of the power-ramping experiments conducted on both the steels explained earlier, fresh laser processing experimentation has been conducted on the same grounded steel specimens with a constant laser power density of $1.75 \times 10^{6} \mathrm{~W} / \mathrm{cm}^{2}$ and varying laser interaction duration between $3.33-100 \mathrm{~ms}$. The range was chosen in a way to cover the spectrum of no-hardening regime to substantial melting regime. Figure 3 and Figure 4 depict the surface morphologies and 3D surface topological profiles obtained with variation in interact- 

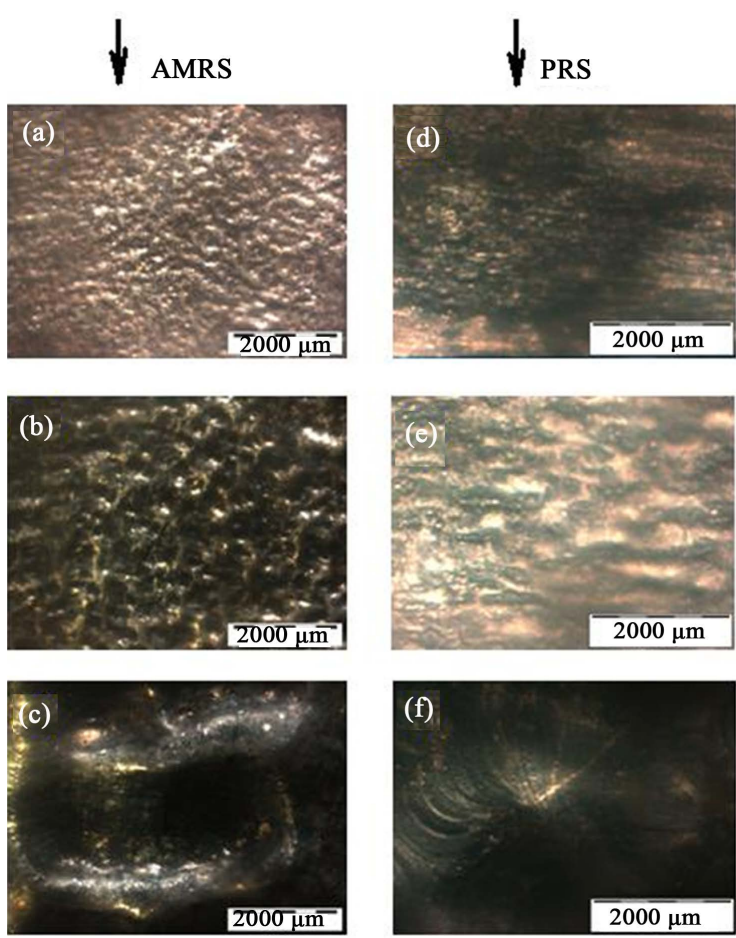

Figure 3. Surface morphologies of as-treated specimens processed with different interaction times: (a) AMRS (20 ms); (b) AMRS (33.3 ms); (c) AMRS (100 ms); (d) PRS (20 ms); (e) PRS (33.3 ms); (f) PRS (100 ms).
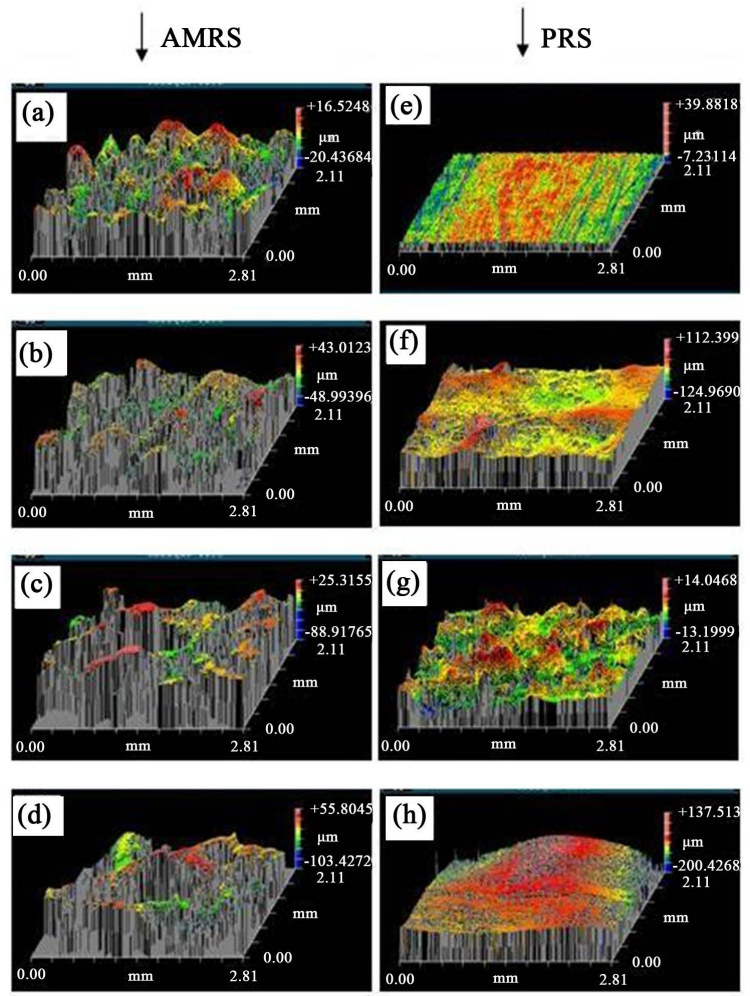

Figure 4. Surface topographic profiles of laser treated PRS and AMRS steels processed with different interaction times: (a) AMRS (20 ms); (b) AMRS (25 ms); (c) AMRS (33.3 ms); (d) AMRS (50 ms); (e) PRS (20 ms); (f) PRS (25 ms); (g) PRS (33.3 ms); (h) PRS (50 ms). 
tion time. Topographic and morphological features of laser treated surfaces processed with $3.33 \mathrm{~ms}$ are not depicted here as no significant variations could be observed in them as compared to that of untreated substrate surfaces owing to very low interaction time involved in the process. 3D optical surface topographic profiles for treated surfaces processed with interaction time of $100 \mathrm{~ms}$ are also not depicted as the surfaces obtained were extremely rough with heavy undulations and could not facilitate to collect sufficient points to obtain an effective topographic profile.

It is clear from Figure 3 that the type of steel as well as interaction time significantly influences the morphology of the treated surface. Indeed $20 \mathrm{~ms}$ interaction time is sufficient enough to eliminate grinding furrows present in the unaffected substrate of both the steels as evident from Figure 3(a) and Figure 3(d). However, many protrusions with rough texture is visible in treated surface of AMRS (Figure 3(a)) compared to the dark smooth surface with no protrusions in PRS (Figure 3(d)). This could be possibly due to the occurrence of melting in AMRS in contrast to transformation hardening (without any melting) in PRS. Indeed, wide gap in solidus temperatures (depicted in Table 3) of PRS and AMRS contributed to this effect. The corresponding topographic profiles of these surfaces (Figure 4(a) and Figure 4(e)) further corroborate these changes that manifest on account of enhancement in surface temperature. These asperities (crests and troughs) were observed to be many and well ordered in AMRS steel, although their density decreasing with increasing interaction time, as compared to their corresponding surface morphologies of PRS. Apparently, the average surface roughness $\left(R_{a}\right)$ and surface waviness $\left(\mathrm{W}_{\mathrm{a}}\right.$ ) values got increased from untreated surface of $1.2 \mu \mathrm{m} \mathrm{R} \mathrm{R}_{\mathrm{a}}$ and $2.4 \mu \mathrm{m} \mathrm{W}$ to $6.4 \mu \mathrm{m} \mathrm{R}_{\mathrm{a}}$ and $74 \mu \mathrm{m}$ $\mathrm{W}_{\mathrm{a}}$ in AMRS (processed with $100 \mathrm{~ms}$ ) and $4.4 \mu \mathrm{m} \mathrm{R} \mathrm{R}_{\mathrm{a}}$ and $38 \mu \mathrm{m} \mathrm{W}_{\mathrm{a}}$ in PRS (processed with $100 \mathrm{~ms}$ ) respectively. This evidently shows that, apart from chemical composition and thermophysical properties of steel, solute concentration, solidification rate $(\mathrm{R})$ and temperature gradient $(\mathrm{G})$ in the melt pool determine the morphology of the laser-treated surface. Further explanation to these effects on resulting surface texture is described later with detailed SEM, EDS and XRD analysis.

One unique feature, reported for the first time, that can be observed in laser melted surfaces of AMRS (evident from 3D surface topographic profiles presented in Figure 4(a)-(d), is the exorbitant growth of height of well aligned protrusions with increase in interaction time. A measure of this surface roughness parameter, termed as PV, (the distance between peak height in crest to center of valley depth, a texture parameter), averaged from three different regions has been evaluated and co-related with melt-depth in Figure 5. It is clear that with increase in interaction time, both PV and melt-depth values increased in AMRS as well as PRS on account of enhanced melting. No melting was observed in PRS until $25 \mathrm{~ms}$ interaction duration on account of high solidus temperature. Although, in AMRS, melt depth $\left(D_{\mathrm{M}}\right)$ gradually increased from about $35 \mu \mathrm{m}$ (processed with $20 \mathrm{~ms}$ ) to about $495 \mu \mathrm{m}$ (processed with $100 \mathrm{~ms}$ ), its PV enhanced exorbitantly from $180 \mu \mathrm{m}$ (processed with 20 $\mathrm{ms}$ ) to about $715 \mu \mathrm{m}$ (processed with $100 \mathrm{~ms}$ ). This indicates formation of protruded crests (domes) of greater heights in AMRS as compared to their corresponding PRS counterparts. This trend with presence of many visible protrusions of greater heights is also evident from 3D topographic profiles, of AMRS as compared to PRS. The protruded crest was observed to be present in nearly central region of PRS melted surface and its height

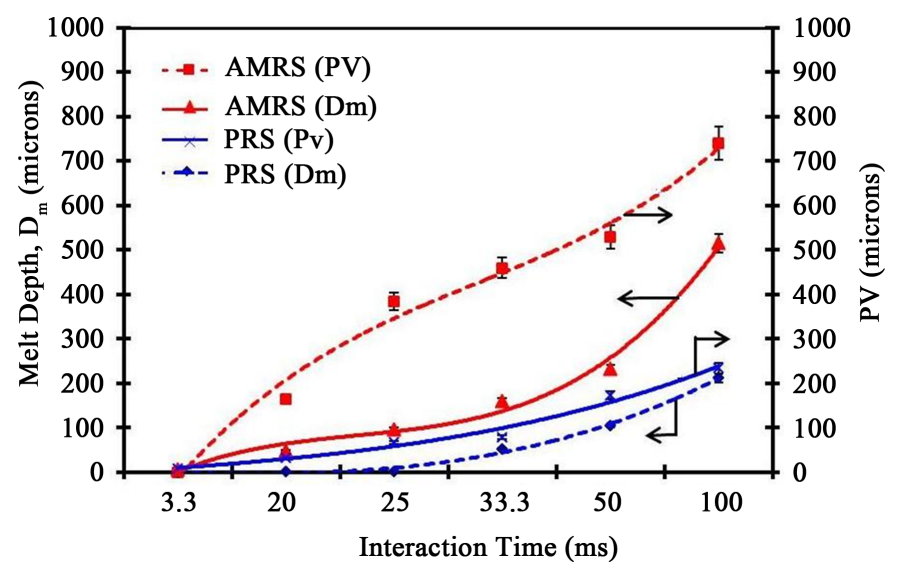

Figure 5. Influence of interaction time on melt-depth and surface roughness parameter $(\mathrm{PV})$ on laser treated PRS and AMRS. 
enhanced gradually with interaction time as compared to many self-aligned domes in AMRS. Similar effects of crest-to-valley heights (although to a lesser values) were reported in laser melted tool steel surfaces processed with YAG laser under pulsed mode and attributed to solidification and evaporation effects associated with thermal accumulation patterns [2]. The melted surface of AMRS (also evident from surface morphology (Figure 3(c)) processed with $100 \mathrm{~ms}$ exhibited a unique wavy surface texture with enlarged hemi-spherical troughs (with 5-mm diameter) and high protrusions (as high as $630 \mu \mathrm{m}$ ). Possibly, interaction of a multi-mode diode laser beam with such high duration on a low thermal conductivity and high thermal expansion co-efficient material like AMRS could induce such textured surface associated with an altogether different solidification mechanism. As melt pool circumference extend with increased interaction time, the protrusion height increases due to shear force of fluid flow, consequently, the adjoining trough depth becomes shallower. In a similar study, Semak and co-workers observed similar effects in laser irradiated surface of steel and attributed to factors like material removal and re-solidification mechanisms involved [7].

Generally, with the commencement of melting, few randomly localized melted pockets arise on surface owing to different degree of site-absorptivity associated with the non-uniform energy distribution (practically speaking, energy distribution profile will be with greater non-uniformity at low interaction time) of the laser beam. As a result, differential variation in temperature accumulation happens at few spots within the laser irradiated region leading to formation of few fine domes (crests) and sinks (troughs) in their vicinity. Further with increase in laser-input energy or interaction time, more thermal accumulation occurs with evaporation effects also coming into vogue. This generally happens in the form of crater (trough) in the central region of the irradiated surface for a Gaussian laser source. The vapor pressure induced shock waves generated in the process facilitates flow of the melt from the crater to its periphery and thereby protrusion eruption enhances adjoining the trough. Thus the positive and recursive feedback mechanism of the melt induce such surface morphology constituting wavy patterns is discernible. As similar to melted surfaces of PRS, many studies involving laser melting of steels also reported similar surface morphologies, although with variation, depending on the thermo-physical properties of steel and processing conditions [6] [7] [46] [47]. However, no study in literature reported such unique surface morphologies / textures in steel as observed in AMRS. Although, it is possible to produce textured surfaces with pulsed mode of laser processing or with laser ablation technique utilizing eximer laser, this is first time that AMRS steel could induce such self-aligned textured patterns with high protrusions utilizing a CW laser.

Further SEM, EDS and XRD analyses of the laser treated PRS and AMRS surfaces depicted in Figures 6-8 elucidate the vital importance of chemistry and thermo-physical properties in producing varied textured surfaces and solidification structures. Pores, pits (dark spots) and cracks were observed in all the melted surfaces of AMRS as against crack-free melted surfaces of PRS processed un till $33.3 \mathrm{~ms}$, whereas few cracks were observed in PRS surfaces processed with 50 and $100 \mathrm{~ms}$ interaction times. Indeed, higher the laser energy or interaction time, higher will be the magnitude of thermal stress developed due to steep temperature gradients in the melt surface vicinity and thereby leading to cracking. If the accumulated stresses in melt fall within the yield stress, no cracking could be induced. The cracking propensity was observed to be higher in case of AMRS than PRS. Indeed, cross-sectional micrographs of the laser-treated layers processed with $25 \mathrm{ms,} \mathrm{depicted} \mathrm{later,} \mathrm{evi-}$ dently showed solidification crack penetrating through the substrate in AMRS as compared to crack-free melt layer in PRS. Similar effects of cracking in the laser melted layers were reported in various studies [47]-[49]. Indeed, high negative partitioning co-efficients of $\mathrm{Mn}$ and $\mathrm{C}$ in AMRS melt pool may facilitate in enhancing rupture along grain/sub-grain boundaries in liquid melt. Similar solidification cracking behaviour was also reported in studies involving laser welding/melting of austenitic manganese steels and attributed to lowering of toughness and carbide precipitation in grain boundaries of the melt pool [29] [50]. Indeed, EDS spot analysis of dendritic melted layer of AMRS depicted in Figure 8 showed Mn-rich carbide segregation in interdendritic region.

Further XRD analysis provides insights into the texturing effects of laser treated surfaces. It is clear that the textured surfaces show formation of oxides of Fe in both PRS and AMRS, although with varying degree, depending on the laser interaction time. No oxide phases were observed in PRS and AMRS surfaces processed with $3.33 \mathrm{~m} / \mathrm{s}$ indicating hardly any effect of the surface due to laser irradiation. Furthermore, iron oxides formed were always higher on PRS surfaces than in AMRS counterparts processed with similar interaction times. This could be attributed to the presence of high Mn content in AMRS and its ease of evaporation. Similar effects on the formation of oxides, although with a varying degree, were reported in laser hardened/melted surfaces of steels and attributed to their chemistry and processing conditions [40] [51]. A close look at the XRD patterns 
$\downarrow$ AMRS
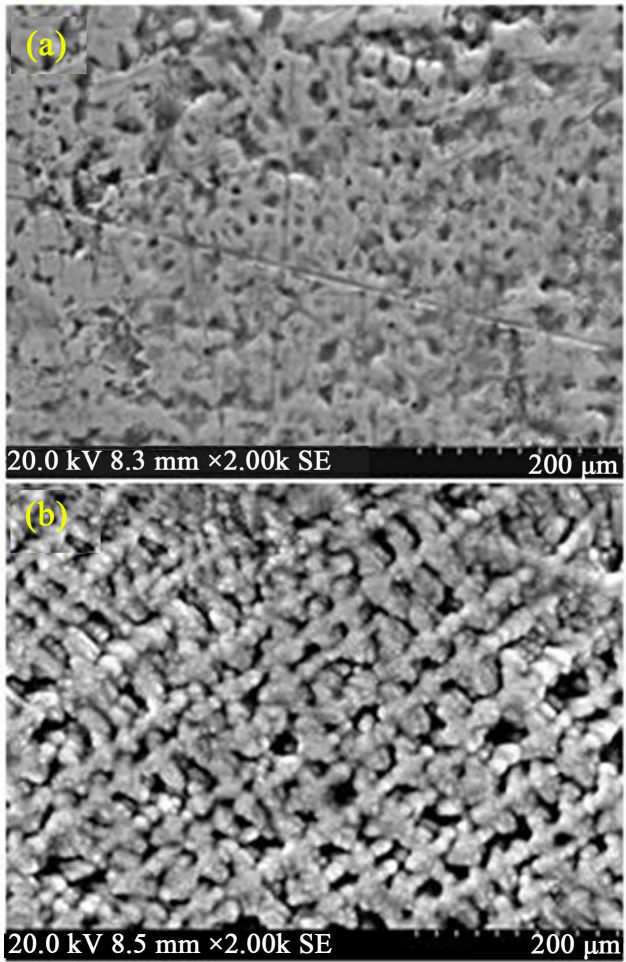

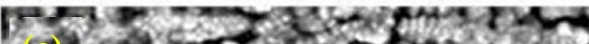

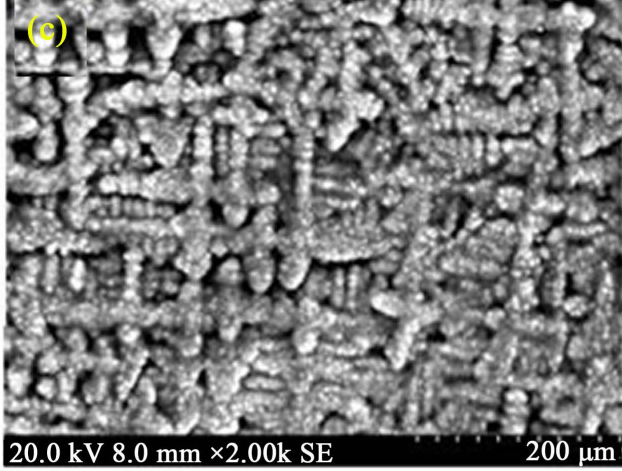

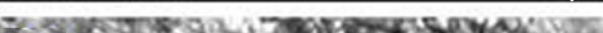

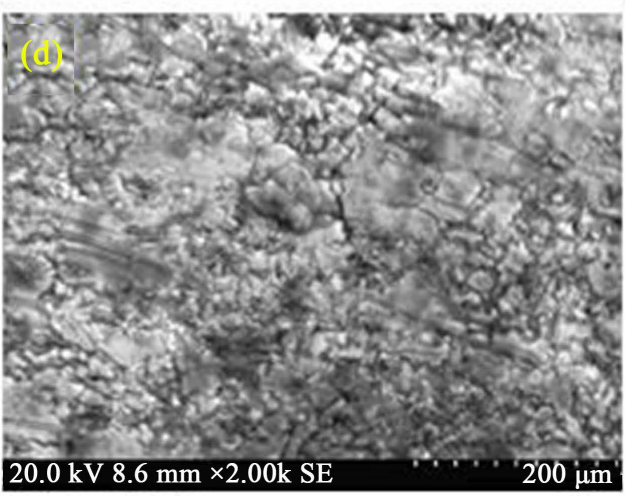

Figure 6. High magnification SEM surfaces of laser-treated PRS and AMRS steels processed with different interaction times: (a); AMRS (20 ms); (b) AMRS (25 ms); (c) AMRS (33.3 ms); (d) AMRS (50 ms); (e) PRS; (20 ms) (f) PRS (25 ms); (g) PRS (33.3 ms); (h) PRS (50 ms).
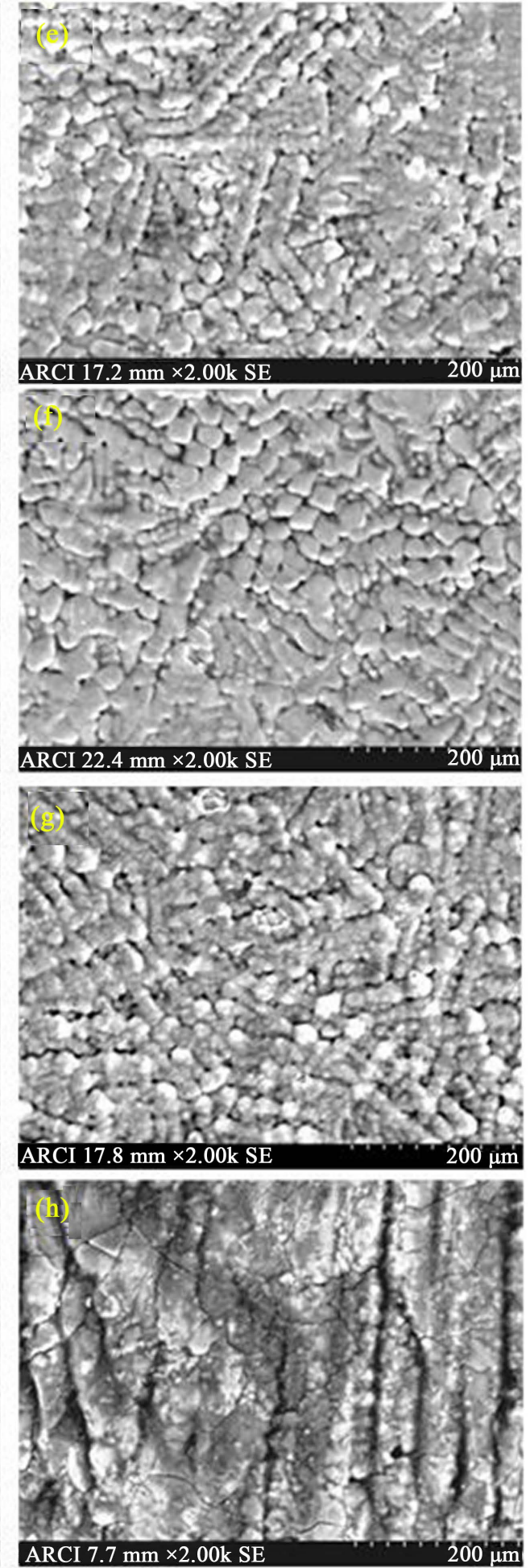


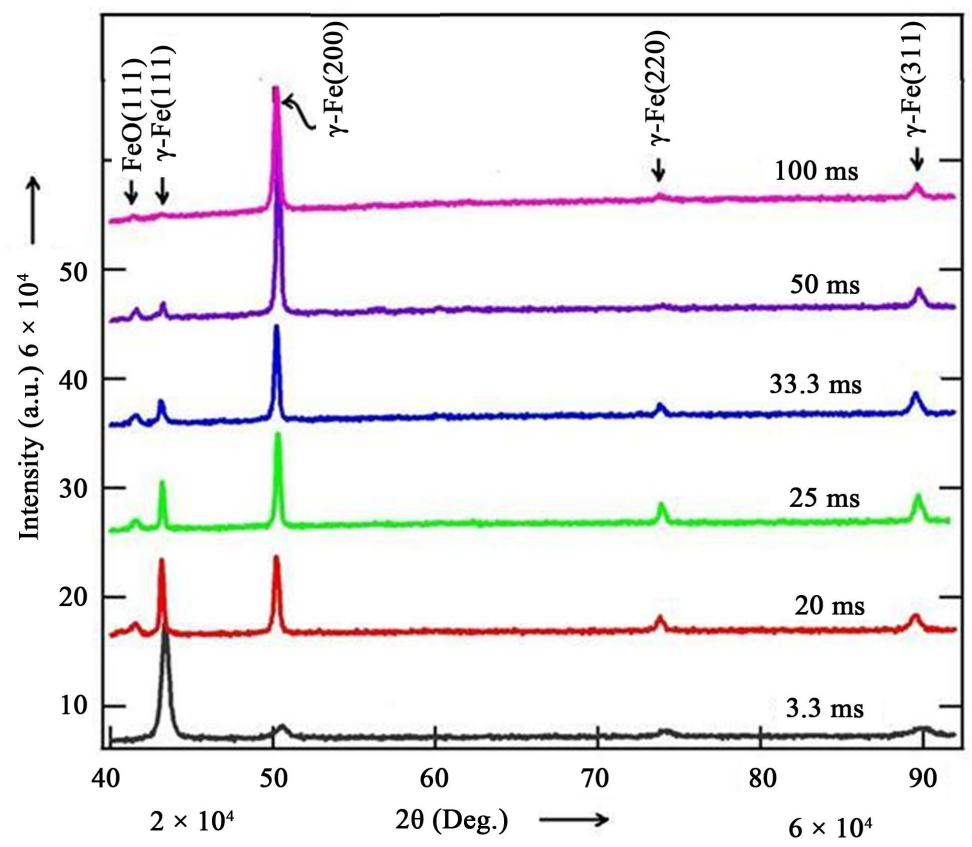

(a)

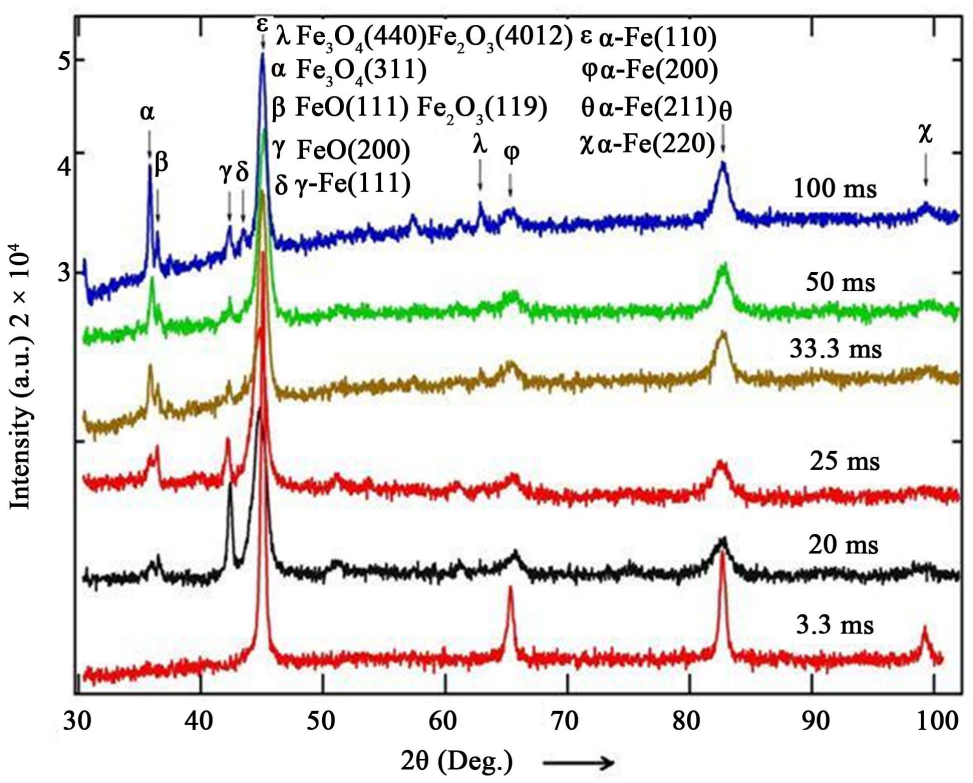

(b)

Figure 7. X-Ray Diffraction patterns of as-treated surfaces processed under different interaction times: (a) AMRS; (b) PRS.

(Figure 7(a)) of AMRS surfaces (processed under different interaction times) showed formation of only austenite phase $(\gamma-\mathrm{Fe})$ and no peaks of either $\alpha^{\prime}$-martensite/ $\varepsilon$-martensite or carbides being detected. This shows that laser melting of AMRS in our case did not induce martensitic transformation, as reported by other studies, owing to austenite stabilization [23] [48]. The XRD patterns of laser melted PRS indicating significant peak shifting as well as peak broadening in almost all $\alpha$-Fe peaks, suggests, formation of martensite with grain refinement as compared to untreated substrate. Indeed, the high cooling rates associated with laser treatment process did facilitate martensitic transformation in PRS owing to its above room temperature $\mathrm{M}_{\mathrm{s}}$. Various studies on laser melting/hardening also reported such martensitic transformation in carbon steels [40] [41]. 


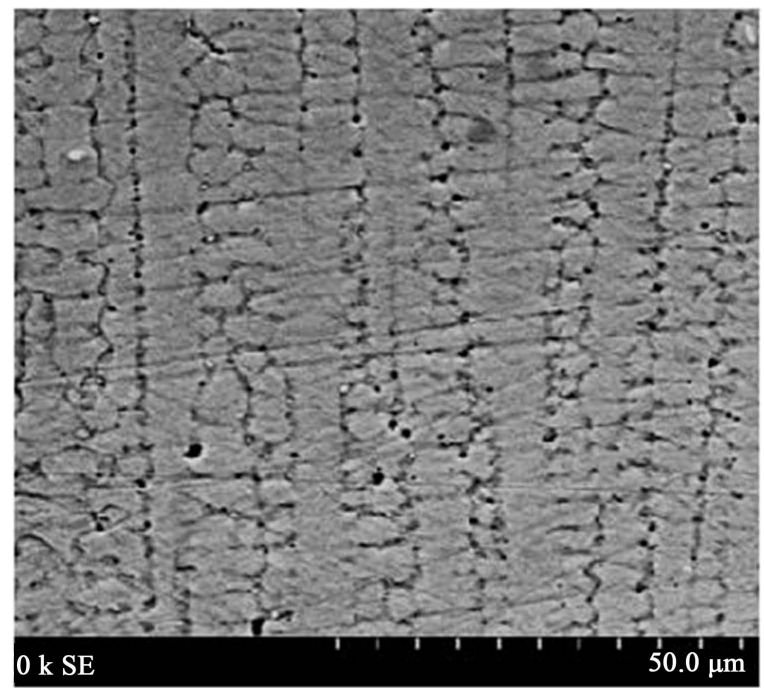

\begin{tabular}{|l|c|c|c|c|c|}
\hline Region & $\mathrm{C}$ & $\mathrm{O}$ & $\mathrm{Si}$ & $\mathrm{Mn}$ & $\mathrm{Fe}$ \\
\hline Dendrite & 3.86 & 0.01 & 0.53 & 10.67 & 83.78 \\
\hline Inter-dendritic region & 10.31 & 0.02 & 0.58 & 15.31 & 73.95 \\
\hline
\end{tabular}

Figure 8. Cross-sectional SEM microstructure and EDS analysis of textured AMRS processed with 25 ms duration.

One striking unique morphological feature that could be observed in the high magnification SEM surface of AMRS processed with $25 \mathrm{~ms}$ (Figure 6(b)) is the uniformly self-aligned textured free surface with epitaxial $\gamma$-Fe crystals with preferred crystallographic orientation. This textured effect got disoriented in different directions (random disorientation of $\gamma$-Fe crystals) with further increase in interaction time of $33.3 \mathrm{~ms}$, evident from Figure 6(c). This shows that there exists a threshold interaction time (possibly $25 \mathrm{~ms}$ ), wherein the resolidified surface could be textured in the fashion observed. With further increase in interaction time of $50 \mathrm{~ms}$, the textured free surface pattern disappeared, possibly due to leveling of thermal accumulation effects. A close look at XRD patterns of treated surfaces with different interaction times (illustrated in Figure 7(a)) indicated gradual reduction in peak intensity of $\gamma$ - $\mathrm{Fe}(111)$ at the expense of increase in intensity in other direction of (200). This texture development evaluated by normalizing (111) peak intensity of other peaks of (200), (220) and (311) of treated surface indicated in Figure 9(a) further corroborate effect of interaction time on evolving preferred crystallographic growth direction of $\gamma$-Fe dendrites. This suggests that the preferred growth direction of $\gamma$-Fe crystals is necessarily in the order of (200) with increase in laser interaction time. Similar variation of crystallographic texture was observed in a recent study conducted on cold worked Hadfield laser-clad coatings, although with a presence of few martensitic transformation peaks [48]. In their study, it was observed that higher the deformation of cold work carried out in laser-clad coating, higher the texturing effect in dendrites of $\gamma$-Fe and attributed to dislocation and twinning effects.

Although free surface texturing effect reduced with increase in interaction time after $20 \mathrm{~ms}$, the strength of the crystallographic texturing effect continuously increased with interaction time, with most influenced directional growth being in (200) direction. In a similar reported study of laser melting of $0.86 \% \mathrm{C}-26 \% \mathrm{Mn}$ steel, similar unidirectional cellular/dendritic growth was observed when processed at rapid solidification conditions [22]. As crystal growth along $\langle 100\rangle$ is most preferred in FCC material, strongest textured influence could be seen in Fe (200) $)_{\gamma}$ of laser melted AMRS. Similar textured surfaces with protrusion of austenite crystals were also reported in rapidly solidified $\mathrm{Fe}-\mathrm{Cr}-\mathrm{Mn}-\mathrm{C}$ steel ribbons produced by melt-spinning when cast with high speeds, although, they had not presented the textured images [23]. They attributed to the presence of high manganese content $(>18$ $\mathrm{Wt} \%$ ) coupled with estimated high cooling rate in range of $10^{5}-10^{6} \mathrm{~K} / \mathrm{s}$ for the dendritic growth of austenite 


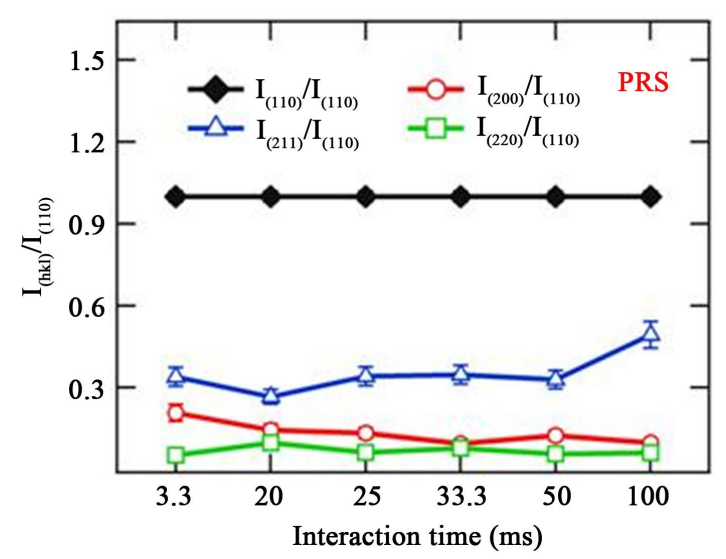

(a)

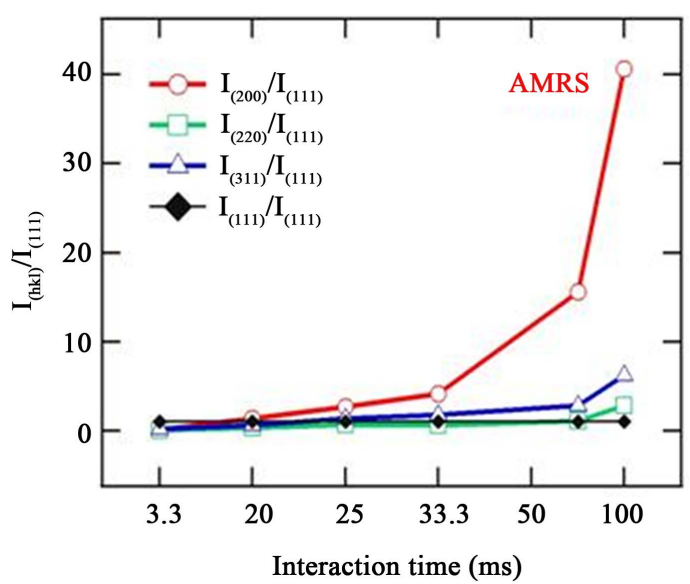

(b)

Figure 9. Influence of interaction time on texture development (variation in intensity distribution of various crystallographic planes normalized to (111) in AMRS and (110) in PRS): (a) PRS; (b) AMRS.

crystals with preferred crystallographic orientation.

The solidification morphologies of melts are basically governed by the ratio of temperature gradient $(\mathrm{G})$ and solidification rate $(\mathrm{R})$, termed as G/R. Basically, an elevated thermal gradient in the melt is desired to facilitate constitutional super cooling and thereby result in directional solidification. At critical cooling rates, occurrence of solidification in localized sites and evaporation in the surrounding area result in thermal accumulation and micro-relief and as a result textured surface, although, chemical inhomogeneity involved in the process determine the effect. Apparently, on account of high G/R coupled with varied partitioning co-efficients of Mn and $\mathrm{C}$ in $\gamma$-Fe, such solidification structure with textured surface effects could be envisaged in AMRS. Although such epitaxial cellular/dendritic solidification structures with textured free surfaces were reported in studies involving irradiation of materials like superalloy, $\mathrm{ZnO}, \mathrm{ZrO}_{2}$, structural steel, platinum and stainless steel with $\mathrm{CO}_{2}, \mathrm{YAG}$, Excimer and Fiber lasers under pulsed/Continuous Wave processing modes [3]-[6] [52], it is first time that an austenitic manganese steel under CW mode diode laser processing produced such self-organized structures. Indeed, the rectangular multi-mode diode laser spot produced with collimation and focusing optics being scanned at very low interaction time could virtually induce the irradiance effect of a packet of few micron-sized Gaussian beam spots (basically structured from arrays of single diode emitters of few micron size spaced in few micron distances) to induce such highly localized solidification/evaporation effects as similar to ablation utilizing Excimer laser. Few studies involving laser melting of $\mathrm{Al}-\mathrm{Cu}, \mathrm{Al}-\mathrm{Nb}$ and $\mathrm{Ti}-\mathrm{Al}$ also reported similar texturing effects with directional solidification and attributed to the prevailing high cooling rates coupled with wide difference in thermal properties of solutes in the melt [17] [19]. 


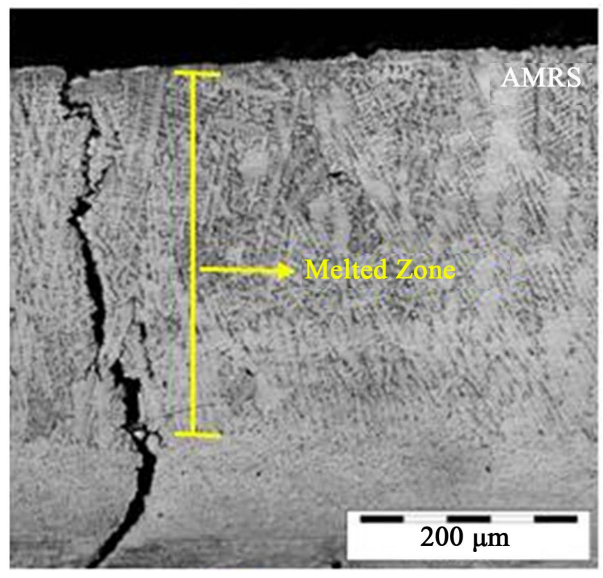

(a)

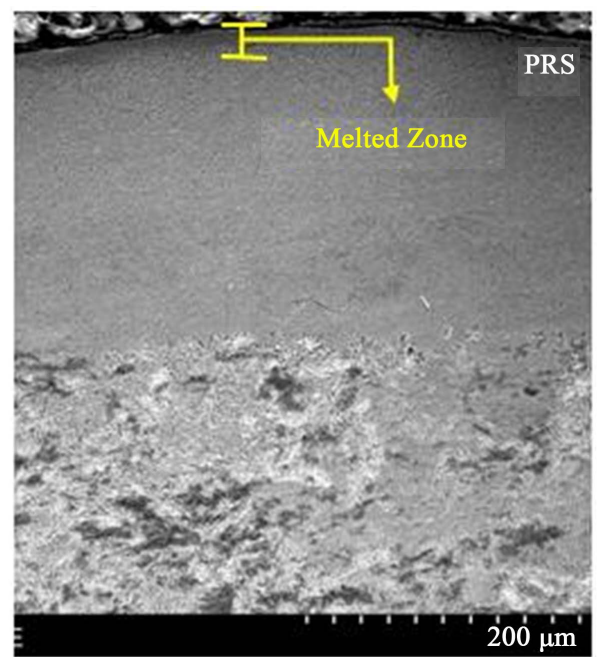

(b)

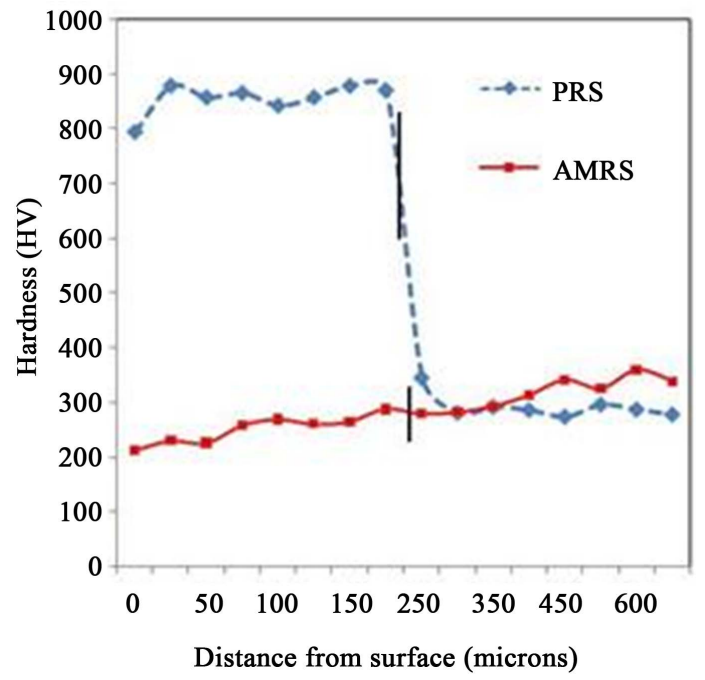

(c)

Figure 10. Cross-sectional micrographs and hardness profiles of steels processed with similar interaction duration of $25 \mathrm{~ms}$ (demarcation lines drawn to indicate melt depth region in micrographs and interface in micro-hardness profiles. 
As compared to the strong texturing influence observed in AMRS with epitaxial dendritic growth of austenite crystals in (200) direction, no texturing influence could be realized in PRS. The treated surface of hardened PRS (without any melting) with 20 ms exhibited randomly disoriented protrusions of oxides, typical of the formation of oxide film texture, reported in many studies involving diode laser hardening of steels [40] [45]. Indeed XRD pattern of the surface exhibited significant iron oxide peaks $\left(\mathrm{Fe}_{3} \mathrm{O}_{4}, \mathrm{Fe}_{2} \mathrm{O}_{3}\right.$ and $\left.\mathrm{FeO}\right)$. Furthermore, broadening of the peak at $44.3^{\circ}$ coupled with significant peak shift indicate martensitic transformation. Thus surface texture of PRS processed with $20 \mathrm{~ms}$ exhibited globules of oxides (brighter spots) and martensites (darker regions). With further increase in interaction time, morphological patterns changed with different globules of martensites and oxides (mixing of different oxides of $\mathrm{Fe}$ with melt). Increase in interaction time lead to increase ${ }^{2} \mathrm{Fe}_{3} \mathrm{O}_{4}$ and $\mathrm{Fe}_{2} \mathrm{O}_{3}$ oxides and decrease of $\mathrm{FeO}$ oxides as evident from the oxide peaks of XRD patterns depicted in Figure 7(b). This is expected owing to increase in oxide dissolution with melt with interaction time and thereby form oxygen-lean iron oxide phases. Similar effect has been reported in the study involving laser treatment of railroad steels by same authors and attributed to varied effects of oxide dissolution in the melt [40].

With further increase in laser interaction time, for example in PRS processed with $50 \mathrm{~ms}$, the morphological pattern has got totally changed from globular texture to irregular undulated one with flaking and cracking. This could possibly happen on account of high evaporation coupled with uneven stress distribution and austenite stabilization. Similar effects of cracking were reported in laser melted steels when excessive melting conditions prevailed [21] [49]. Apparently, a minimal texturing effect in the reverse direction could be observed in $\mathrm{Fe}(200)_{\alpha}$ of PRS as evident from the normalized intensity distribution of various peaks of $\alpha$-Fe presented in Figure 7(b). With increase in interaction time, intensity of $\alpha$-Fe in (200) direction reduced marginally, plausibly on account of martensitic transformation (c-axis dilation) and stabilization of austenite. On the whole, no significant texturing effect could be observed in laser melted PRS, with the exception of globular morphologies associated with porous oxide film formation. Indeed, presence of low $\mathrm{C}$ and $\mathrm{Mn}$, as compared to that AMRS, did induce planar growth and as a result no dendritic/cellular solidification structures.

\subsection{Cross-Sectional Microstructure and Hardness Evaluation}

Further to comprehend the microstructural variations in the subsurface of treated layers, comparison in terms of cross-sectional microstructure and hardness profile has been analyzed by considering a typical layer processed with similar interaction time of $25 \mathrm{~ms}$. Figure 10 illustrates cross-sectional microstructures and hardness profiles of the treated layers. As indicated previously, solidification crack penetrating though the substrate is clearly visible in AMRS, as against no such cracking in PRS. Plausibly, toughness of the melted layer (22-micron depth) in PRS is sufficient enough to accommodate the induced stress to avoid cracking. Conversely, solidification cracking is easily possible in AMRS on account of lowering of toughness in melted layer associated with higher extent of austenite destabilization and segregation of carbides along the grain boundary. Hardness distribution in the treated layer of PRS indicated $840-880 \mathrm{HV}$ in hardened region and $795-820 \mathrm{HV}$ in melted region as compared to the substrate hardness of 260 - $290 \mathrm{HV}$ (near tempered region). Vast hardness improvement in transformation hardened region of PRS could be due to martensitic transformation associated with high cooling rates of the laser treatment process and $263^{\circ} \mathrm{C} \mathrm{M}_{\mathrm{s}}$ temperature of the steel. Marginal hardness reduction in melted region of PRS steel could be on account of soft austenite retention observed as per XRD analysis. Similar effects of hardness variation in both hardened and melted regions are reported in various studies involving laser hardening of steels [40] [41]. Conversely, hardness values reduced with distance from melted/substrate interface in laser treated layer of AMRS processed with $25 \mathrm{~ms}$. Indeed destabilization of austenite with carbon loss and segregation of carbides in interdendritic boundary could reduce hardness in melted microstructure. Similar reduction in hardness of melted austenitic steels was reported in various studies and attributed to loss of carbon/carbides and reduced austenite stability with solidification rate [53] [54].

\section{Conclusions}

Depending upon the laser interaction time, melting induced distinguishably different microstructural transformations and surface morphological effects in austenitic and pearlitic steels. Measurement of temperature during laser irradiation exhibited higher temperature on pearlitic steel surface than in austenitic one due to lowering of effective thermal conductivity and enhanced laser absorptivity associated with higher oxide film formation. At critical processing condition (interaction time), a unique self-aligned wavy pattern in melted surface was observed 
in austenitic steel with highly protruded crests as compared to moderately rough texture in pearlitic steel. Melt depth with high peak-to-valley height texture parameter was always found higher in austenitic steel than in pearlitic one owing to low solidus temperature and low thermal conductivity. No martensitic transformation was observed in austenitic steel as compared to full martensitic transformation produced in pearlitic steel.

Laser surface melting of austenitic manganese steel with appropriate power density and cooling rate determined by laser interaction time resulted in textured free surface with growth of protrusions increasing with melt depth. Strong texturing effect in (200) plane was observed with laser melting of austenitic steel and this effect increased with increase in interaction time at the expense of (111) plane. The microstructure also showed preferred growth of cellular-dendrites of austenite in direction perpendicular to laser scanning direction. In contrast, no texturing effect with any preferential growth could be observed in pearlitic steel.

\section{Acknowledgements}

The authors gratefully acknowledge the director of ARCI for granting permission to publish this work. They are also thankful to Mr. Manish Tak and Mr. Shyam Rao of Center for Laser Processing of Materials for assistance in conducting laser experiments and metallographic analysis.

\section{References}

[1] Cui, C.Y., Hu, J.D., Liu, Y.H., Gao, K. and Guo, Z.X. (2008) Morphological and Structural Characteristics of Different Oxides Formed on the Stainless Steel by Nd:YAG Pulsed Laser Irradiation. Applied Surface Science, 254, 6537-6542. http://dx.doi.org/10.1016/j.apsusc.2008.04.020

[2] Hua, M., Shao, T.M., Hong, Y.T. and Man, E.C.H. (2004) Influence of Pulse Duration on the Surface Morphology of ASSAB DF-2 (AISI-01) Cold Work Steel Treated by YAG Laser. Surface and Coatings Technology, 185, 127-136. http://dx.doi.org/10.1016/j.surfcoat.2004.01.007

[3] Brown, S.W., Fisk, A.E. and Reutzel, E.W. (2012) Fs Laser Surface Processing of Platinum. Proceedings of 31 st International Congress on Applications of Lasers and Electro-Optics (ICALEO), Anaheim, 23-27 September 2012, 710719.

[4] Lickschat, P., Schille, J., Muller, M., Weissmantel, S. and Reisse, G. (2012) Comparative Study on Microstructuring of Steel Using Pico- and Femtosecond Laser Pulses. Proceedings of 31st International Congress on Applications of Lasers \& Electro-Optics (ICALEO), Anaheim, 23-27 September 2012, 1261-1268.

[5] Jiang, Y.J., Zhao, Y. and Xie, S. (2012) Improving the Wettability on $\mathrm{ZnO}$ and $\mathrm{ZrO}_{2}$ Single Crystal Surface by Laser Irradiation. Proceedings of 31 st International Congress on Applications of Lasers and Electro-Optics (ICALEO), Anaheim, 23-27 September 2012, 943-946.

[6] Chikarakara, E., Naher, S. and Brabazon, D. (2011) Process Mapping of Laser Surface Modification on AISI 316L Stainless Steel for Biomedical Applications. Applied Physics A, 101, 367-371.

http://dx.doi.org/10.1007/s00339-010-5843-5

[7] Semak, V.V., Damkroger, B. and Kempka, S. (1999) Temporal Evolution of the Temperature Field in the Beam Interaction Zone during Laser Material Processing. Journal of Physics D: Applied Physics, 32, 1819-1825. http://dx.doi.org/10.1088/0022-3727/32/15/309

[8] Riveiro, A., Soto, R., Comesana, R., Boutinguiza, M., del Val, J., Quintero, F., Lusquinos, F. and Pou, J. (2012) Laser Surface Texturing of Bioactive Materials. Proceedings of 31st International Congress on Applications of Lasers and Electro-Optics (ICALEO), Anaheim, 23-27 September 2012, 889-895.

[9] Kac, S. and Kusinski, J. (2004) SEM Structure and Properties of ASP2060 Steel after Laser Melting. Surface and Coatings Technology, 180-181, 611-615. http://dx.doi.org/10.1016/j.surfcoat.2003.10.104

[10] Schille, J., Schneider, L., Hartwig, L., Loeschner, U., Ebert, R., Scully, P., Goddard, N. and Exner, H. (2012) Characterization of Interaction Phenomena in High Repetition Rate Femtosecond Laser Ablation of Metals. Proceedings of 31st International Congress on Applications of Lasers and Electro-Optics (ICALEO), Anaheim, 23-27 September 2012, 949-958.

[11] Cui, C.Y., Hu, J.D., Liu, Y.H., Gao, K. and Guo, Z.X. (2008) Formation of Nano-Crystalline and Amorphous Phases on the on the Surface of Stainless Steel by Nd:YAG Pulsed Laser Irradiation. Applied Surface Science, 254, 6779-6782. http://dx.doi.org/10.1016/j.apsusc.2008.04.069

[12] Paetzel, R. (2002) Comparison Excimer Laser-Solid State Laser. Lambda Physik AG Report.

[13] Boettinger, W.J., Coriell, S.R., Greer, A.L., Karma, A., Kurz, W., Rappaz, M. and Trivedi, R. (2000) Solidification Microstructure: Recent Developments, Future Directions. Acta Materalia, 48, 43-70. http://dx.doi.org/10.1016/S1359-6454(99)00287-6 
[14] Liu, L., Huang, T.W., Qu, M., Liu, G., Zhang, J. and Fu, H.Z. (2010) High Thermal Gradient Directional Solidification and Its Application in the Processing of Nickel-Based Super Alloys. Journal of Materials Processing Technology, 210, 159-165. http://dx.doi.org/10.1016/j.jmatprotec.2009.07.022

[15] Vilar, R., Almeida, A. and Costa, E. (2012) Structure of Ni-Alloys Deposited by Laser Powder Deposition on Single Crystal Superalloy Substrates. Proceedings of 31 st International Congress on Applications of Lasers and Electro-Optics (ICALEO), Anaheim, 23-27 September 2012, 197-204.

[16] Ramirez-Rico, J., de Aellano-Lopez, A.R., Martinez-Fernandez, J., Pena, J.J. and Larrea, A. (2008) Crystallographic Texture in $\mathrm{Al}_{2} \mathrm{O}_{3}-\mathrm{ZrO}_{2}\left(\mathrm{Y}_{2} \mathrm{O}_{3}\right)$ Directionally Solidified Eutectics. Journal of the European Ceramic Society, 28, 26812686. http://dx.doi.org/10.1016/j.jeurceramsoc.2008.04.015

[17] Vilar, R., Conde, O. and Franco, S. (1999) Crystallographic Structure of $\mathrm{Al}_{3} \mathrm{Nb}$ in Laser-Processed Al-Nb Alloys. Intermetallics, 7, 1227-1233. http://dx.doi.org/10.1016/S0966-9795(99)00025-4

[18] Berjeza, N.A., Velikevitch, S.P., Mazhukin, V.I., Smurov, I. and Flamant, G. (1995) Influence of Temperature Gradient to Solidification Velocity Ratio on the Structure Transformation in Pulsed- and CW-Laser Surface Treatment. Applied Surface Science, 86, 303-309. http://dx.doi.org/10.1016/0169-4332(94)00446-3

[19] Liu, Y.C., Guo, Z.Q., Wang, T., Xu, D.S., Song, G.S., Yang, G.C. and Zhou, Y.H. (2001) Directional Growth of Metastable Phase $\gamma$ in Laser-Remelted Ti-Al. Journal of Materials Processing Technology, 108, 394-397. http://dx.doi.org/10.1016/S0924-0136(00)00851-7

[20] Bruzzone, A.A.G., Costa, H.L., Lonardo, P.M. and Lucca, D.A. (2008) Advances in Engineered Surfaces for Functional Performances. CIRP Annals-Manufacturing Technology, 57, 750-769. http://dx.doi.org/10.1016/j.cirp.2008.09.003

[21] Lu, Y.C., Jin, C., Lin, T.L., Chen, L.Y. and Su, B.R. (1988) Microstructure and Properties of Epitaxial Layers by Laser Glazing. Materials Letters, 6, 229-232. http://dx.doi.org/10.1016/0167-577X(88)90027-4

[22] Tjong, S.C. and Tsang, H.C. (1993) Laser Surface Melting of an Austenitic Fe-26Mn-7Al-0.9C Alloy. Surface and Coatings Technology, 57, 139-144. http://dx.doi.org/10.1016/0257-8972(93)90030-R

[23] Chen, S.R., Davies, H.A. and Rainworth, W.M. (1999) Austenite Phase Formation in Rapidly Solidified Fe-Cr-Mn-C Steels. Acta Materalia, 47, 4555-4569. http://dx.doi.org/10.1016/S1359-6454(99)00334-1

[24] Seblin, B., Jahazeeah, Y., Sujeebun, S., Manohar, K. and Wong, B. (2004) Material Science MECH2104 Report: Steel. $1-21$.

[25] Marshall, A.J. (2011) Technical Data Sheet: Hadfield Steel.

[26] Senthil Selvan, J., Subramanian, K. and Nath, A.K. (1999) Effects of Laser Surface Hardening on En18 (AISI 5135) Steel. Journal of Materials Processing Technology, 91, 29-36. http://dx.doi.org/10.1016/S0924-0136(98)00430-0

[27] ASM International (1990) ASM Handbook, Vol. 1: Properties and Selection Iron Steels and High Performance Alloys. ASM International, Geauga County.

[28] Shariff, S.M., Pal, T.K., Padmanabham, G. and Joshi, S.V. (2011) Comparative Study on Dry Sliding Wear Behavior of Various Railroad Steels. Journal of Tribology (Transactions of ASME), 133, Article ID: 021602. http://dx.doi.org/10.1115/1.4003485

[29] Peters, N.W. (2005) Report: The Performance of Hadfield's Manganese Steel as It Relates to Manufacture.

[30] Srivastava, A.K. and Das, K. (2008) Microstructural Characterization of Hadfield Austenitic Manganese Steel. Journal of Materials Science, 43, 5654-5658. http://dx.doi.org/10.1007/s10853-008-2759-y

[31] US Department of Transportation (2002) Report-DOT/FRA/ORD-01/15: Steel Alloys with Lower Bainite Microstructures for Use in Railroad Cars and Track.

[32] Jost, N. and Schmidt, I. (1986) Friction-Induced Martensitic Transformation in Austenitic Manganese Steels. Wear, 111, 377-389. http://dx.doi.org/10.1016/0043-1648(86)90134-1

[33] Totten, G.E. (2007) Steel Heat Treatment Handbook. 2nd Edition, Steel Heat Treatment-Metallurgy and Technologies, 561-706.

[34] Ham, Y.-S., Kim, J.-T., Kwak, S.-Y., Choi, J.-K. and Yoon, W.-Y. (2010) Critical Cooling Rate on Carbide Precipitation during Quenching of Austenitic Manganese Steel. China Foundry, 7, 178-182.

[35] Norberg, L. (2010) Fatigue Properties of Austenitic Mn-Steel in Explosion Depth Hardened Condition. Master's Thesis, Chalmers University of Technology, Gothenburg.

[36] Owen, W.S. and Grujicic, M. (1999) Stain Aging of Austenitic Hadfield Manganese Steel. Acta Materalia, 47, 111-126. http://dx.doi.org/10.1016/S1359-6454(98)00347-4

[37] Rittel, D. and Roman, I. (1989) Tensile Deformation of Coarse-Grained Cast Austenitic Manganese Steels. Materials Science and Engineering: A, 110, 77-87. http://dx.doi.org/10.1016/0921-5093(89)90159-7 
[38] Smith, R.W. (2003) WB F Mackay, Austenitic Manganese Steels-Developments for Heavy Haul Rail Transportation. Canadian Metallurgical Quarterly, 42, 333-342. http://dx.doi.org/10.1179/cmq.2003.42.3.333

[39] Subhi, A.D. and Abdulrazaq, O.A. (2007) Phase Transformation of Hadfield Manganese Steels. Engineering and Technology, 25, 808-814.

[40] Shariff, S.M., Pal, T.K., Padmanabham, G. and Joshi, S.V. (2013) Influence of Chemical Composition and Prior Microstructure on Diode Laser Hardening of Railroad Steels. Surface and Coatings Technology, 228, 14-26. http://dx.doi.org/10.1016/j.surfcoat.2013.03.046

[41] Shariff, S.M., Pal, T.K., Padmanabham, G. and Joshi, S.V. (2010) Sliding Wear Behaviour of Laser Surface Modified Pearlitic Rail Steel. Surface Engineering, 26, 199-208. http://dx.doi.org/10.1179/174329409X455458

[42] Clayton, P. (1980) The Relations between Wear Behavior and Basic Material Properties for Pearlitic Steels. Wear, 60, 75-93. http://dx.doi.org/10.1016/0043-1648(80)90250-1

[43] Chen, H.-T., Lin, J.-H. and Xu, X.-J. (2013) Analytical Estimates of Surface Conditions in Laser Surface Heating Process with Experimental Data. International Journal of Heat and Mass Transfer, 67, 936-943. http://dx.doi.org/10.1016/j.ijheatmasstransfer.2013.08.093

[44] Iordanova, I. and Antonov, V. (2008) Surface Oxidation of Low Carbon Steel during Laser Treatment: Its Dependence on Initial Microstructure and Influence on the Laser Energy Absorption. Thin Solid Films, 516, 7475-7481. http://dx.doi.org/10.1016/j.tsf.2008.03.031

[45] Pantsar, H. and Kujanpaa, V. (2006) Effect of Oxide Layer Growth on Diode Laser Beam Transformation Hardening of Steels. Surface and Coatings Technology, 200, 2627-2633. http://dx.doi.org/10.1016/j.surfcoat.2004.09.001

[46] Hua, M., SeDao, Shao, T.M. and Tam, H.Y. (2007) Surface Transformation of DF-2 Steel after Continuous Mode Laser Irradiation. Journal of Materials Processing Technology, 192-193, 89-96. http://dx.doi.org/10.1016/j.jmatprotec.2007.04.037

[47] Taha, M.A., Yousef, A.F., Gany, K.A. and Sabour, H.A. (2012) On Selective Laser Melting of Ultra High Carbon Steel: Effect of Scan Speed and Post Heat Treatment. Materialwissenschaft und Werkstofftechnik, 43, 913-923. http://dx.doi.org/10.1002/mawe.201200030

[48] Pelletier, J.M., Oucherif, F., Sallamund, P. and Vannes, A.B. (1995) Hadfield Steel Coatings on Low Carbon Steel by Laser Cladding. Materials Science and Engineering A, 202, 142-147. http://dx.doi.org/10.1016/0921-5093(95)09792-9

[49] Yilbas, B.S., Sami, M. and Shuja, S.Z. (1998) Laser-Induced Thermal Stresses on Steel Surface. Optics and Lasers in Engineering, 30, 25-37. http://dx.doi.org/10.1016/S0143-8166(98)00008-6

[50] Mendez, J., Ghoreshy, M., Mackay, W.B.F., Smith, T.J.N. and Smith, R.W. (2004) Weldability of Austenitic Manganese Steel. Journal of Materials Processing Technology, 153-154, 596-602. http://dx.doi.org/10.1016/j.jmatprotec.2004.04.033

[51] Cui, C.Y., Hu, J.D., Liu, Y.H., Gao, K. and Guo, Z.X. (2008) Microstructure Evolution on the Surface of Stainless Steel by Nd:YAG Pulsed Laser Irradiation. Applied Surface Science, 254, 3442-3448. http://dx.doi.org/10.1016/i.apsusc.2007.11.035

[52] Faucon, M., Desrus, H., Lopez, J. and Kling, R. (2012) Comparison Study of Sub Microstructure Generation on Metals between Femtosecond Ti:Sa Laser and High Repetition Yb Doped Fiber Laser. Proceedings of 31st International Congress on Applications of Lasers and Electro-Optics (ICALEO), Anaheim, 23-27 September 2012, 877-881.

[53] Kwok, C.T., Lo, K.H., Chan, W.K., Cheng, F.T. and Man, H.C. (2011) Effect of Laser Surface Melting on Intergrannular Corrosion Behaviour of Aged Austenitic and Duplex Stainless Steels. Corrosion Science, 53, 1581-1591. http://dx.doi.org/10.1016/j.corsci.2011.01.048

[54] Kwok, C.T., Man, H.C. and Cheng, F.T. (1998) Cavitation Erosion and Pitting Corrosion of Laser Surface Melted Stainless Steels. Surface and Coatings Technology, 99, 295-304. http://dx.doi.org/10.1016/S0257-8972(97)00624-5 